\title{
المترجم القانوني وعقبة نقل الثقافة بين التكافؤ المعجمي والاختلاف الدلالي
}

\section{محمد حمـزة مرابط \\ كلبة الآداب و اللغات مُرات

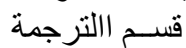

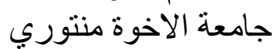 \\ قسنطينة}

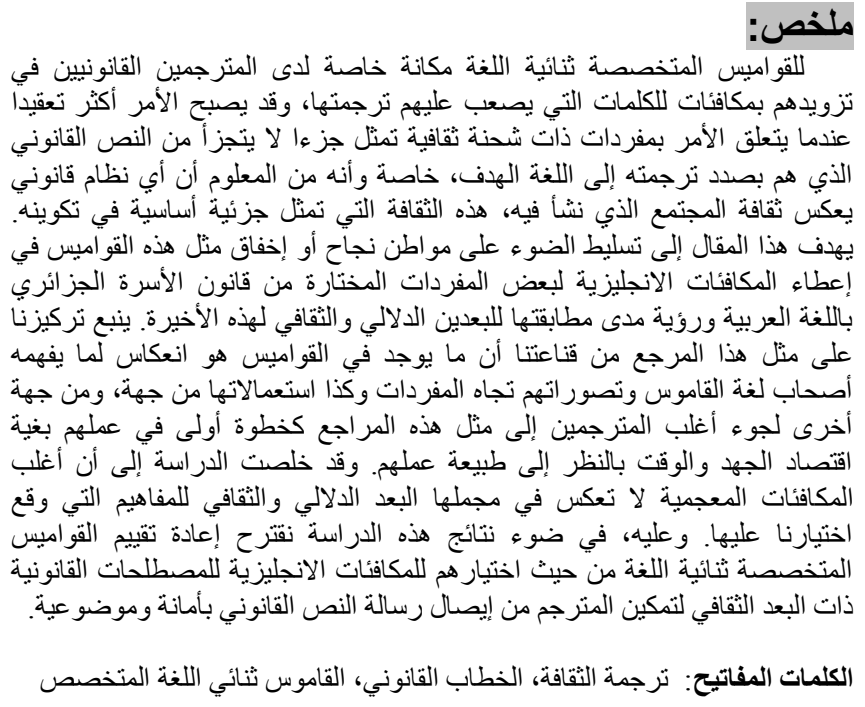

Specialized Bilingual dictionaries play a tremendous role in providing translators with equivalents to concepts that represent an obstacle to the fulfilment of their work. These dictionaries are considered to be the first trustworthy reference for the majority of translators as they reflect the understanding and perceptions of the target language population, in addition to the fact that they save time and effort when dealing with different texts. Rendering culturebound concepts, for one, is considered a major challenge for translators of legal texts because they reflect the uniqueness of a culture for which no identical referents or concepts really exist. Equivalents that are presented in bilingual dictionaries are, at best, approximations of what such culture-bound terms really mean. This paper aims to cast fresh light at some of these inadequacies inherited in translating some culture-bound concepts in legal texts. We recommend, in the light of the results of the present study, to reassess the specialised bilingual dictionaries from the perspective of the selection of English equivalents to Arabic culture-bound legal terms to enable translators to convey the message of such texts faithfully and objectively.

Keywords: Translating culture, Legal discourse, specialized bilingual dictionary 
ومع اتساع حيز البحث وتعديه الجانب اللغوي للعملية الترجمية واتصاله بالعلوم الأخرى، انصب الهنمام

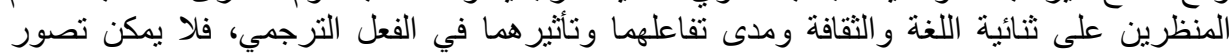

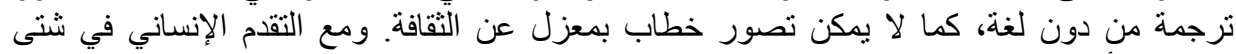

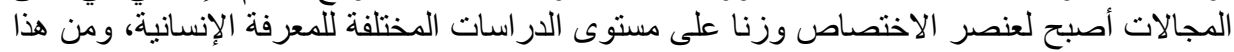

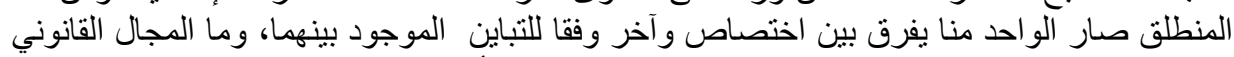

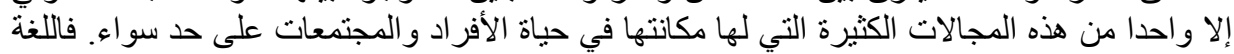

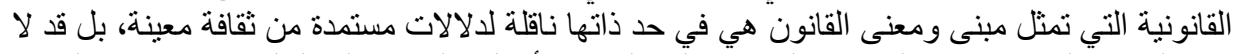

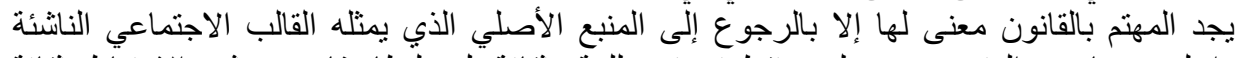

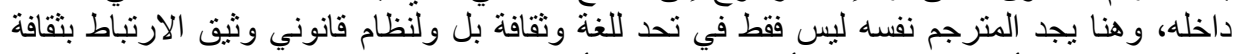

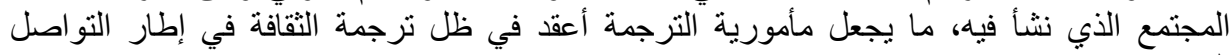

1- المترجم كجسر تواصل بين الثقافات

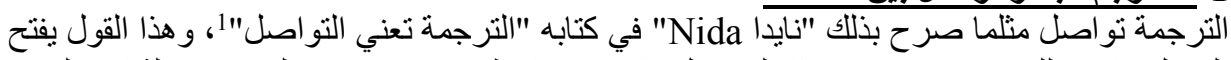

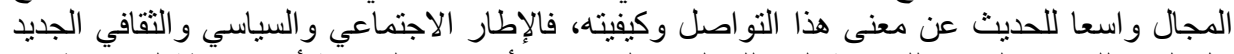

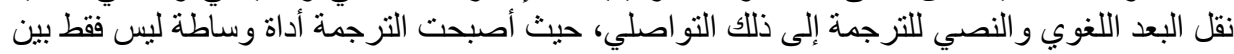

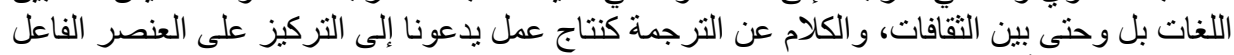

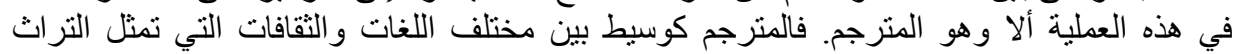

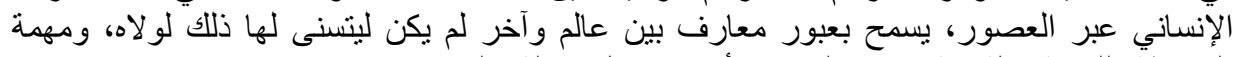

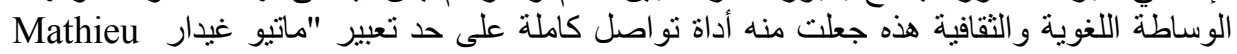

.$^{2}$ Guidère فكون المترجم أداة تواصل بين عالمين، يعد في الأساس الر ابط الذي يجمعهما، فيضع معا أناسا وثقافات

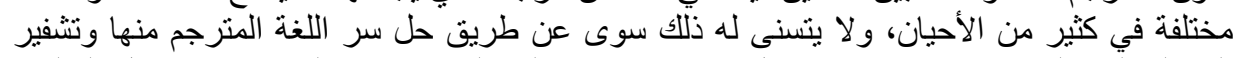

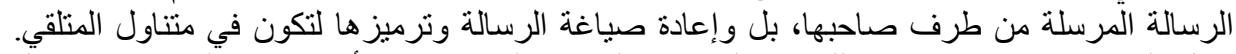

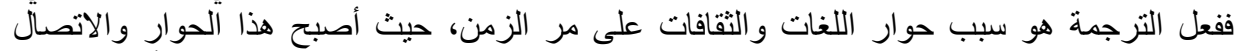

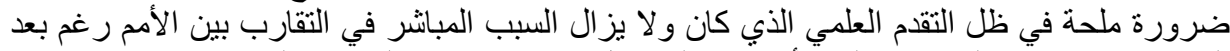

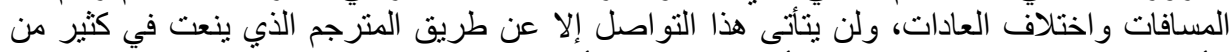

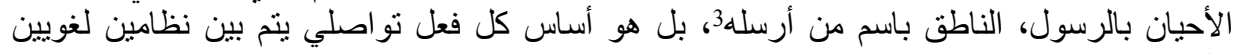
وثقافيين منباينين.

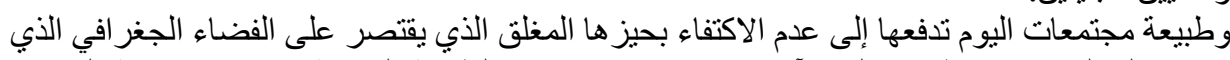

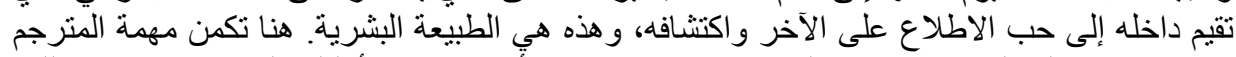

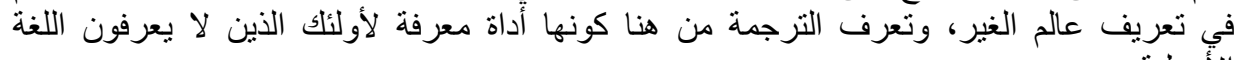

الأصَّلية. تصن.

و عن حديثه حول بقاء واستمر ار الترجمة عبر العصور و عدم توقفها عن خدمة الحضار ات أكد "جورج

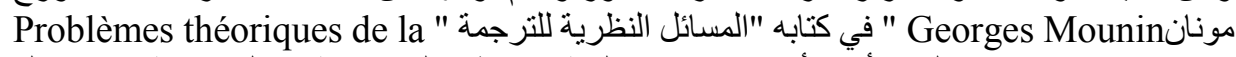
"traduction

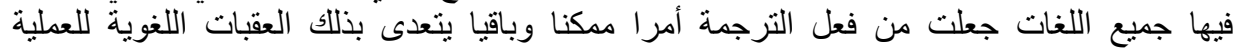

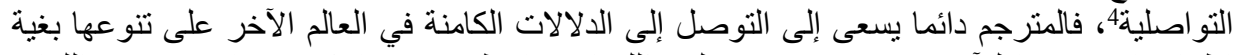

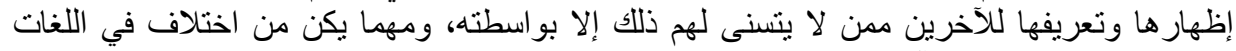

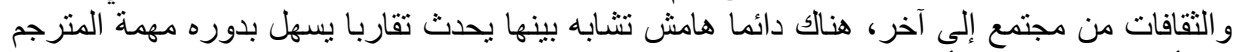

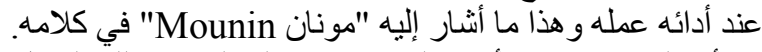

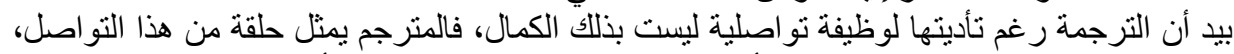

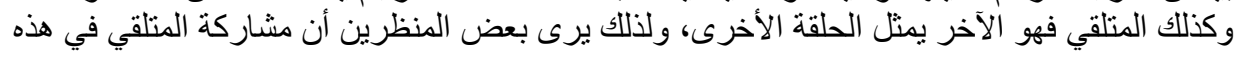


العملية التواصلية يعد من الأولويات، فوجب عليه دائما توسيع معرفته وتحديثها بقراءاته المتتالية، ما

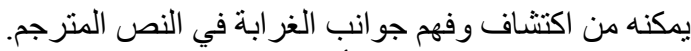

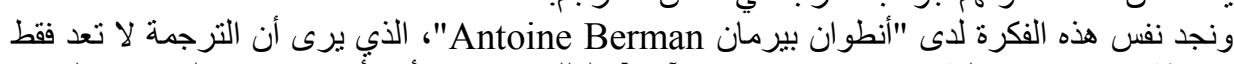

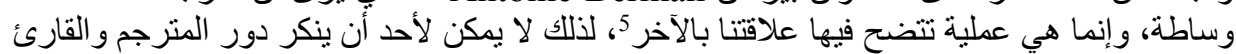

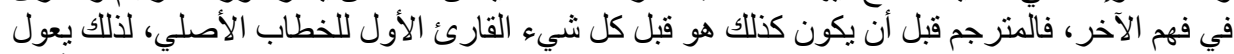

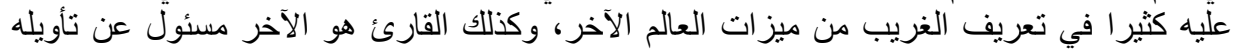

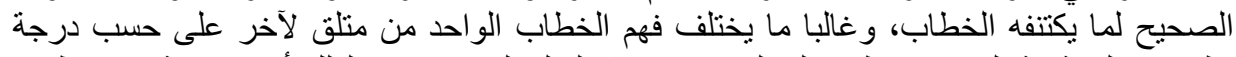

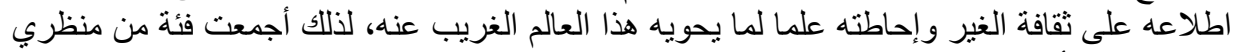

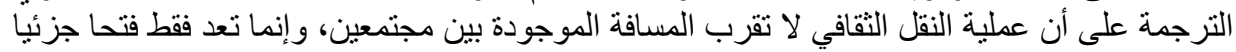

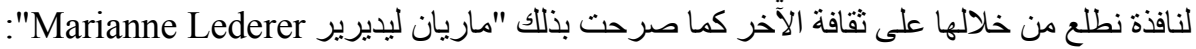
«Le transfert du culturel consiste à apporter au lecteur étranger des connaissances sur un monde qui n'est pas le sien. Cet apport ne comble pas intégralement la distance entre deux mondes, mais entr'ouvre une fenêtre sur la culture originale $»^{6}$

و في خضم الكلام عن نقل الثقافة ذهب بعض دارسي هذا المجال إلى القول بأن مهمة الترجمة هي غلق فئل

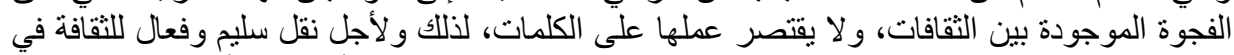

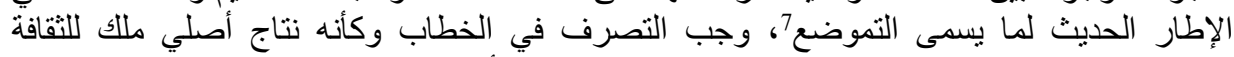

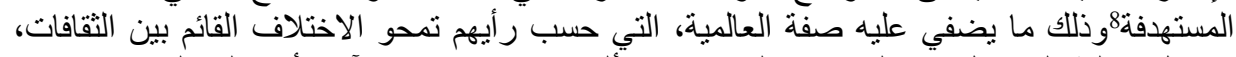

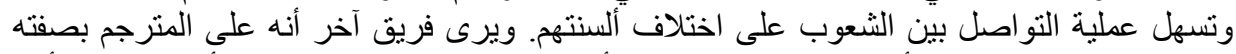

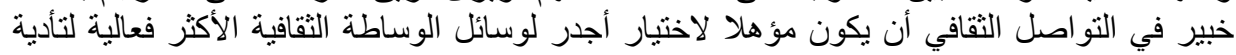

مهمة التو اصل في سياق ثقافي معين.

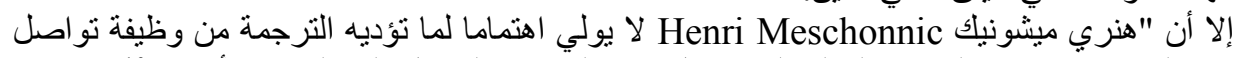

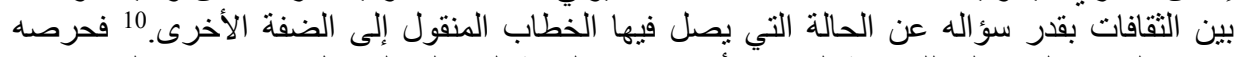

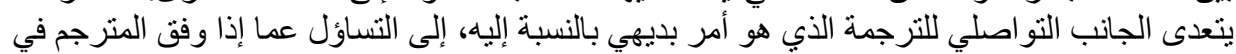

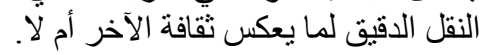

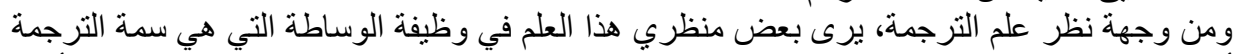

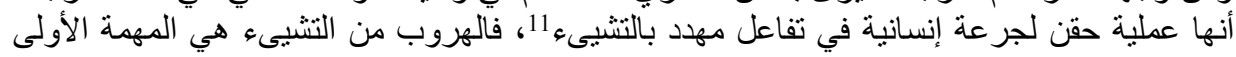

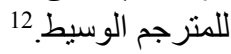

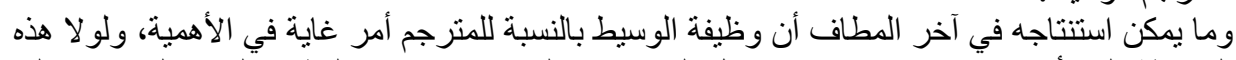

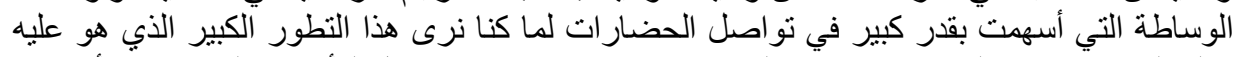

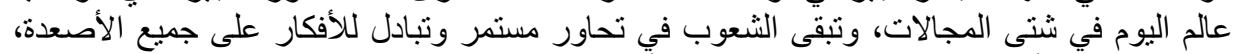

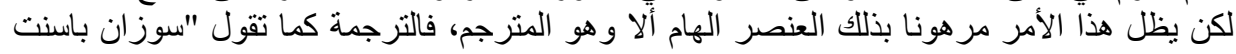
Susan Bassnett 2- عقبة ترجمة العنصر الثقافى في الخطاب القانونى

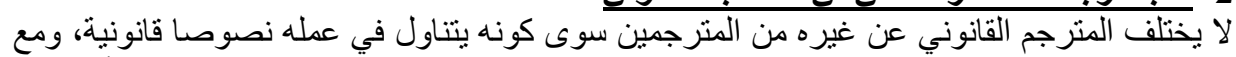

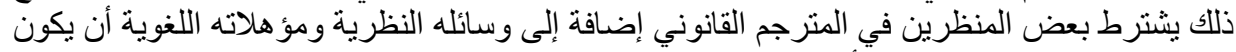

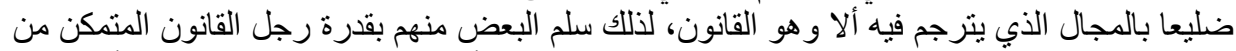

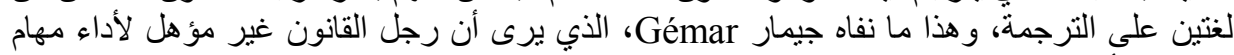

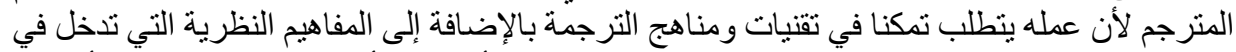

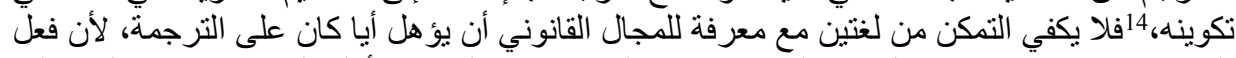

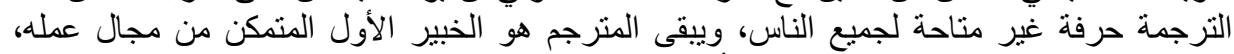
و عموما يمكن القول عن المثرجم القانوني أنه ذللك المترجم الذي تلقى تكوينه كمنرجم عام ثم قام بصقل 


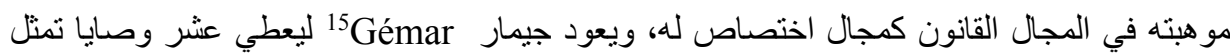

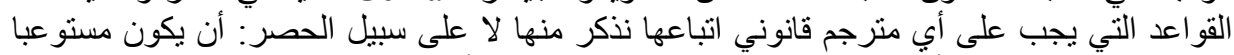

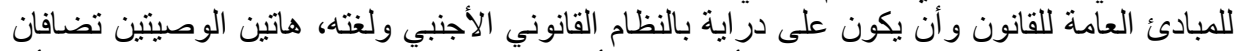

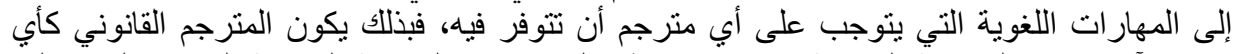

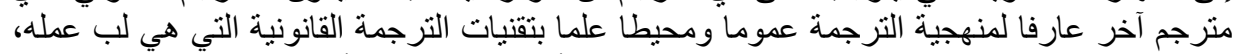

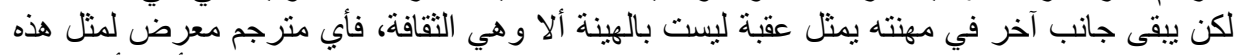

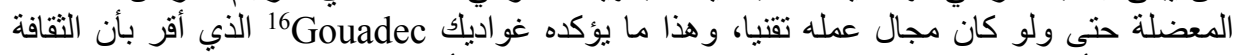

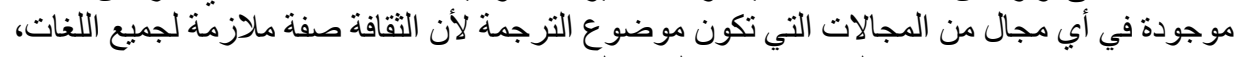

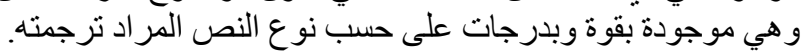

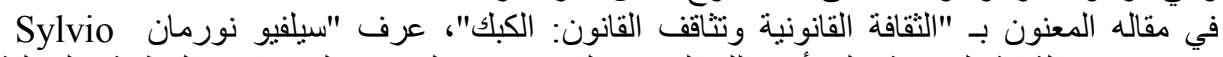

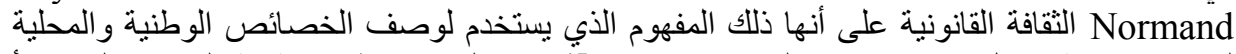

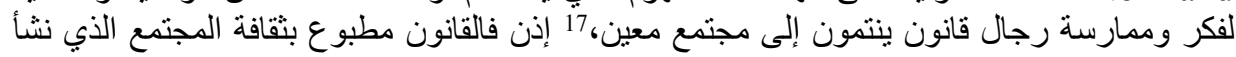

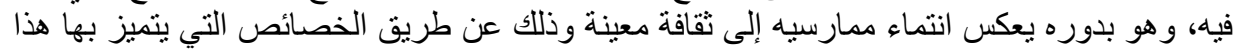

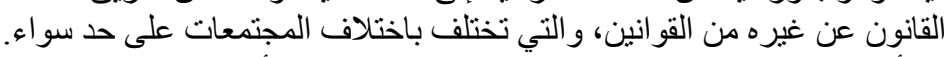

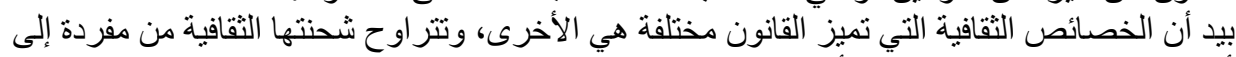

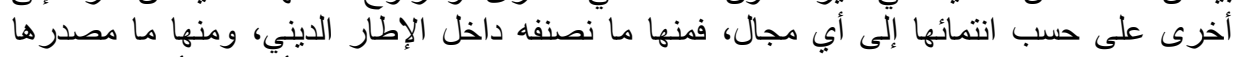

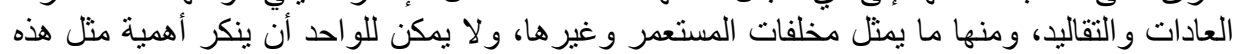

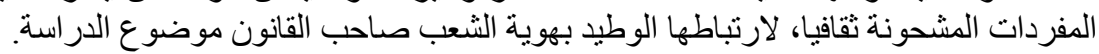

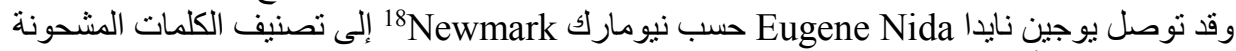

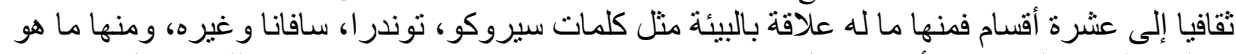

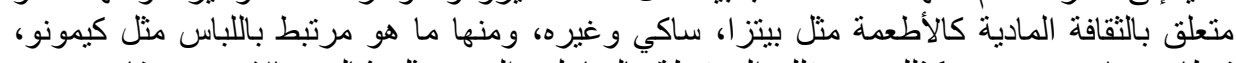

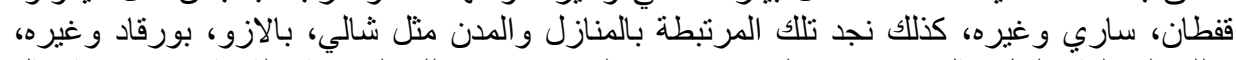

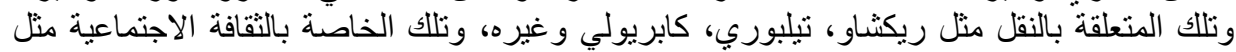

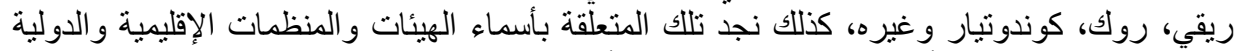

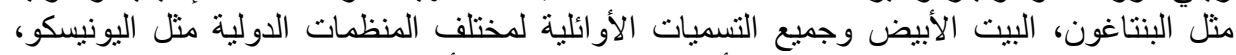

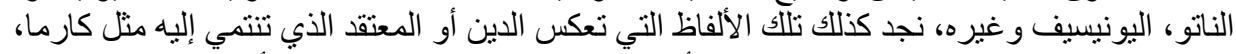

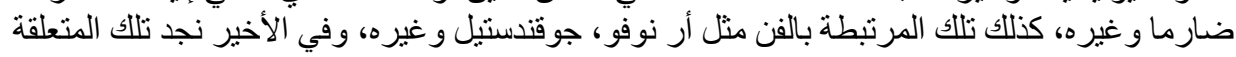

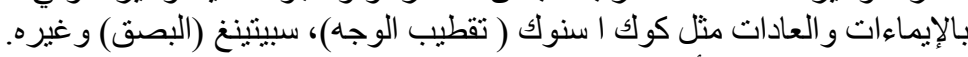

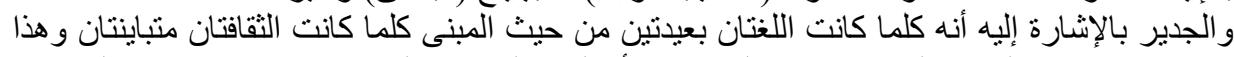

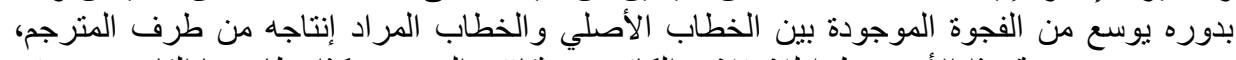

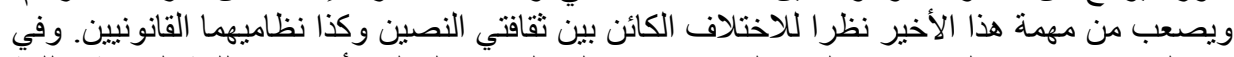

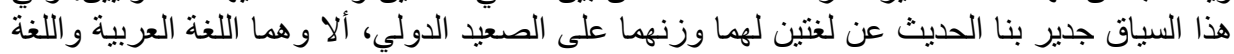

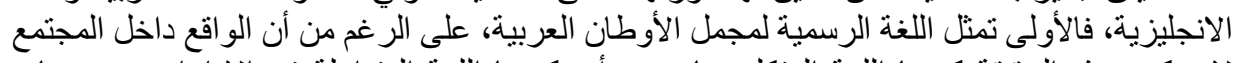

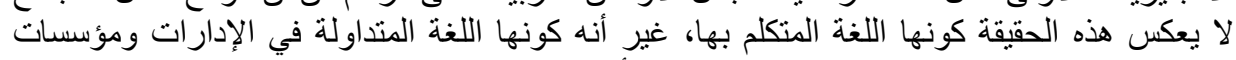

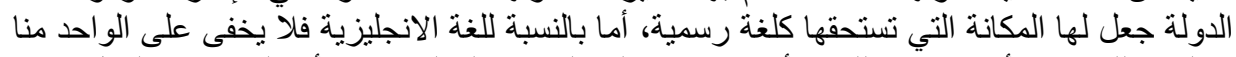

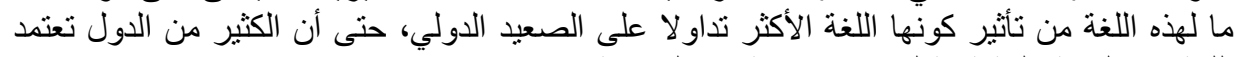
اللغة الانجليزية كلغة ثانية لادى إصدار وثائقها الرسمية.

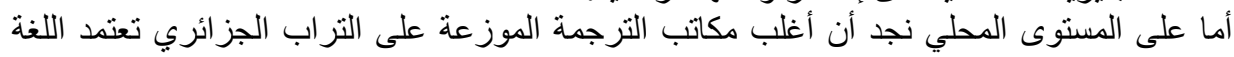

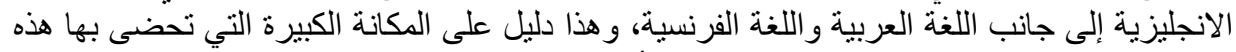

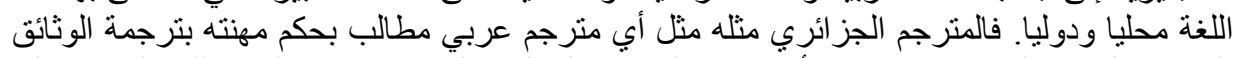

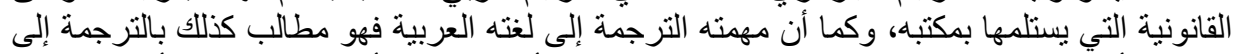
اللغات الأجنيية التي تدخل ضمن إطار لغات عمله. لكن المأمورية تكون أعسر لما ينعلق الأمر بالترجمة 


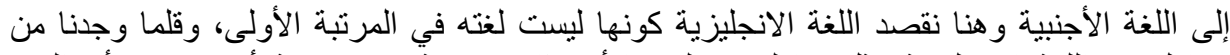

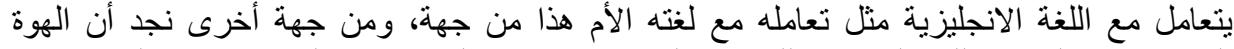

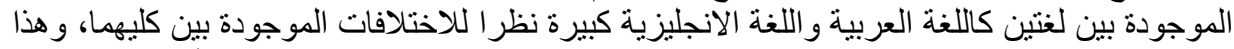

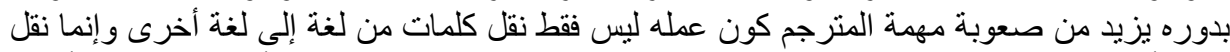

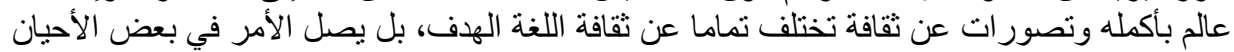

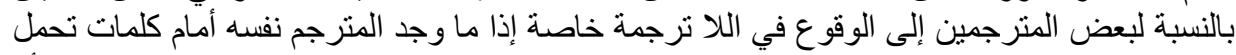

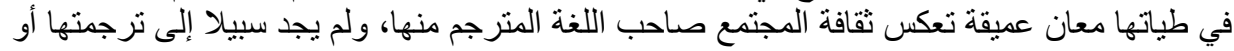

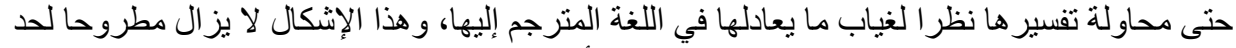

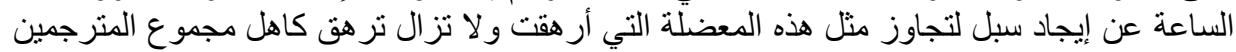

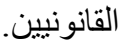

ولا ينكر الواحد منا ما للقو اميس من مكانة لدى المترجمين في تيسبر مهامهم واقتصاد جهدهم ووقتهم،

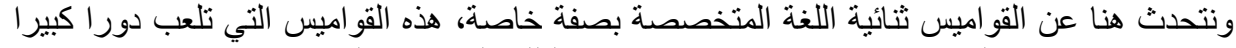

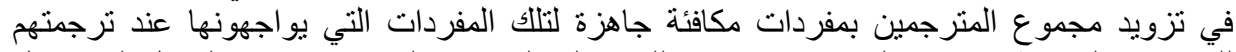

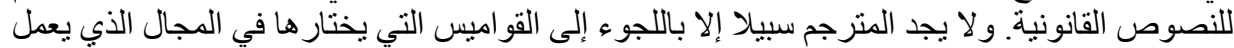

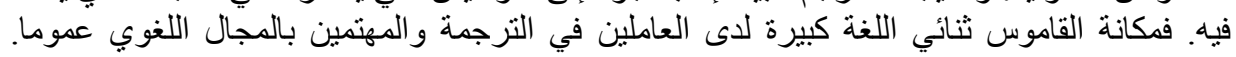

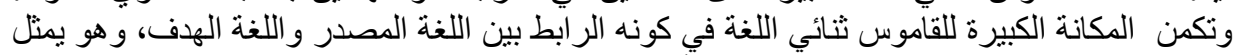

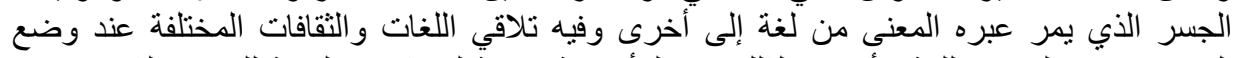

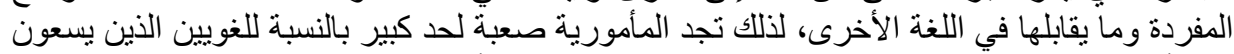

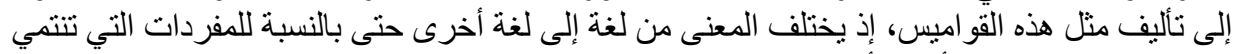

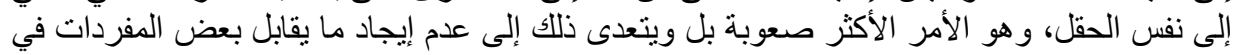

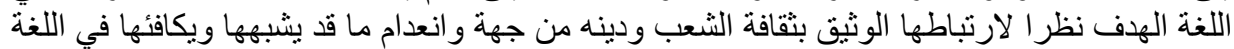

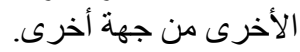

وفي إطار موضوع نقل الثقافة عن طريق الترجمة في السياق القانوني، جدير بنا الإشارة إلى أن هذا

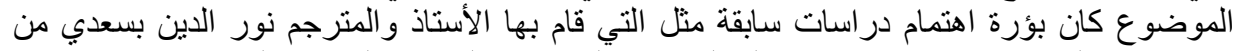

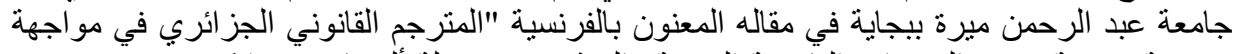

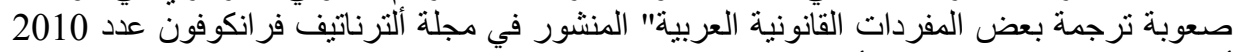

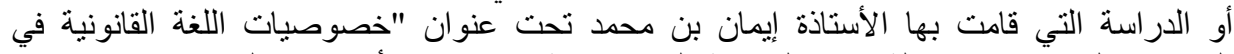

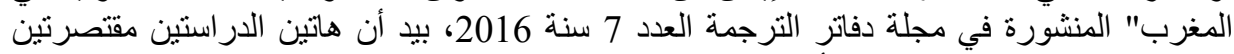

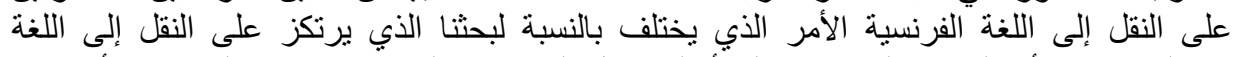

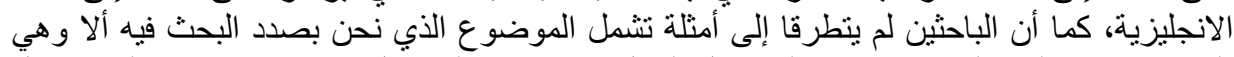

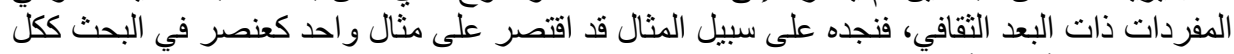

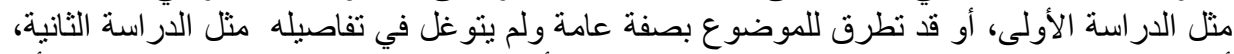

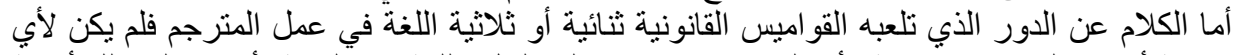

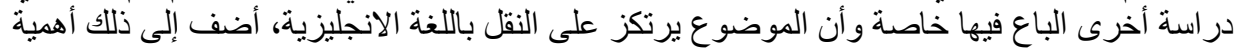

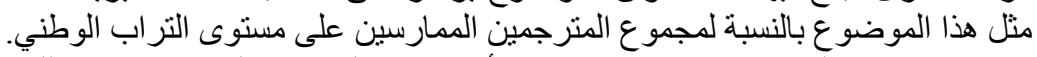

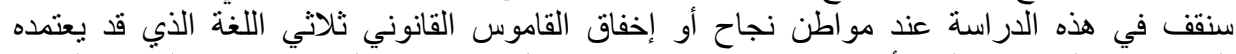

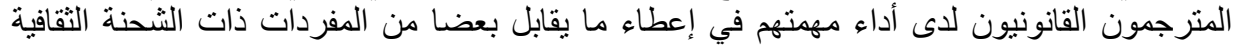

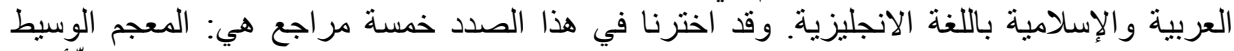

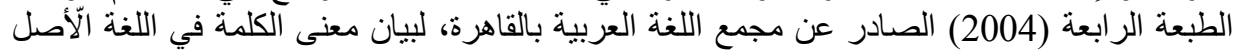

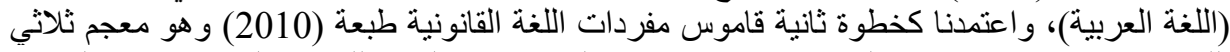

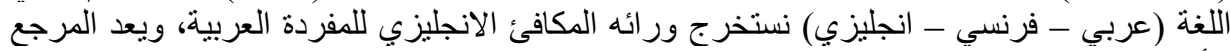
الأهم في بحثنا و الذي يحتمده كثير من المترجمين القانونيين، وكخطوة ثالثية اخترنا ثلاثة قور اميس قانونية 


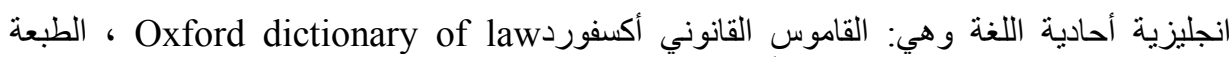

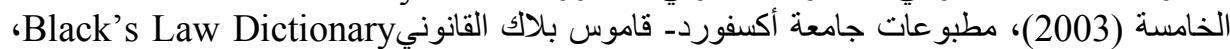

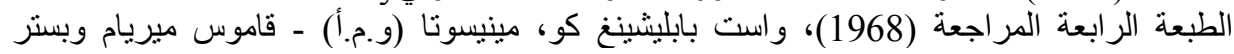
Merriam Webster

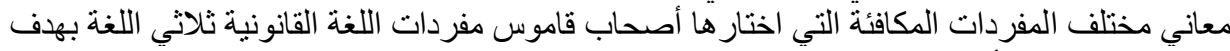

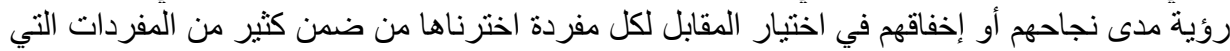

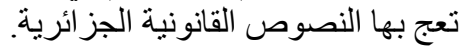

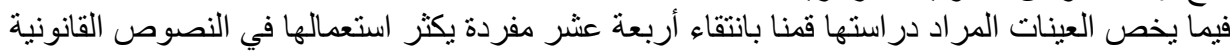

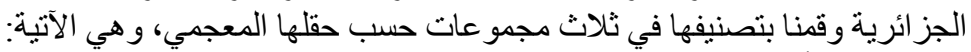
الزجموعة الأولى: (الفاتحة، الصداق، الجهاز، النفقة) التي تنضوي تحت التهي، الحقل المعجمي المرتبط بالزواج.

المجموعة الثنانية: (الولي، الوصي، الضرة، المحرم، العقوق، ولد الفراش) و التي تنضوي تحت الحقل

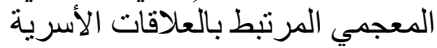

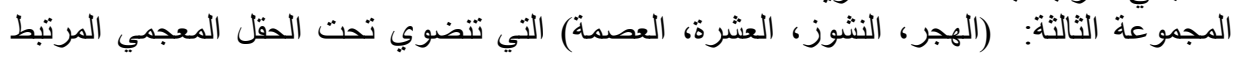

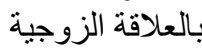

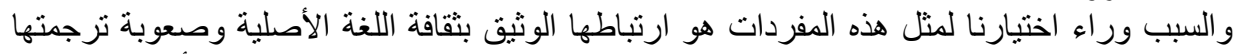

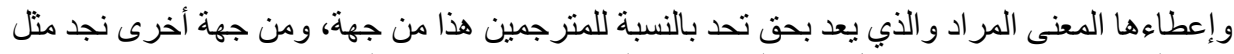

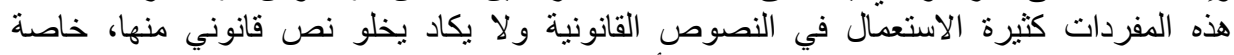

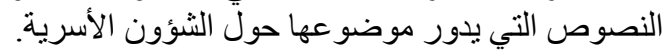

بعد بحثنا في القاموس عن المفردات المختارة بغرض الأسراية. استخر اج ما يقابلها في اللغة الانجليزية وجدنا

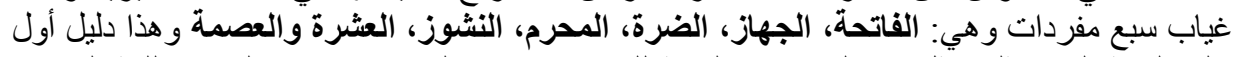

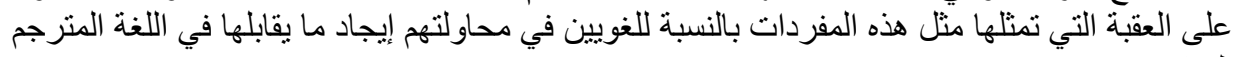
أما بالنسبة للمفردات الأخرى فسنتطرق لها حالة بحالة كالتالي: المفردة الأولى: المغردية

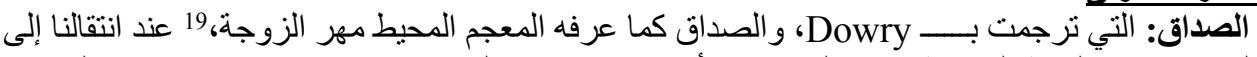

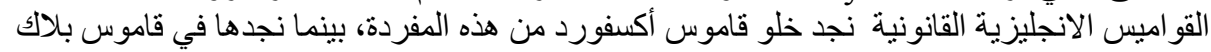

DOWRY: The property which a woman brings to her husband in marriage; now more commonly called a "portion."20

ونجد قاموس ميريام وبستر قد عرفها:

DOWRY: Law: the money, goods, or estate that a woman brings to her husband in marriage ${ }^{21}$

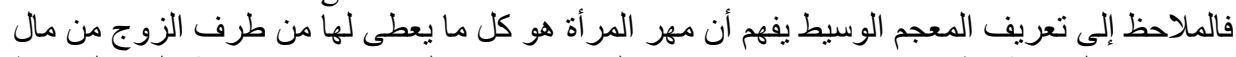

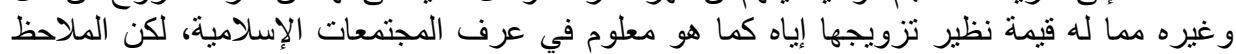

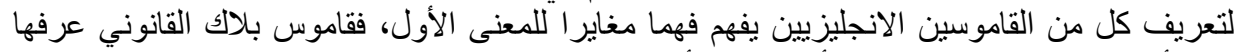

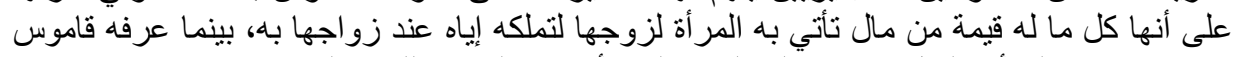

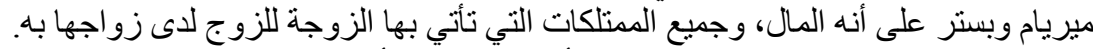

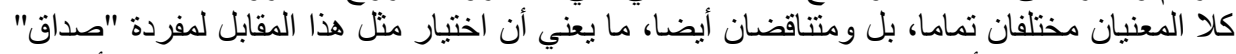

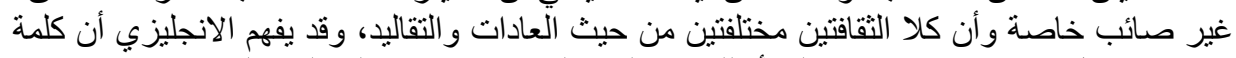

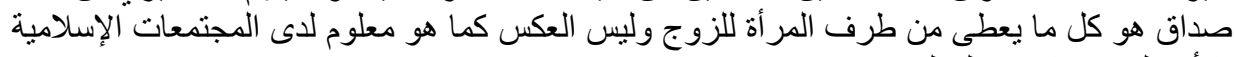

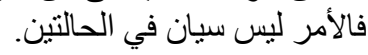


التفقة:ة والتئية: الثفرفها المعجم الوسيط على أنها ما يفرض للزوجة على زوجها من مال للطعام والكساء

و السكنى و الحضانة والي عرفهاء ونحو ها.

تم إعطاء مفردة Alimony كمقابل لهذه المفردة، حيث عند انتقالنا للقو اميس الانجليزية نجد أن قاموس أوكسفورد قد عرفهاء كما يلي:

Alimony $n$. formerly, financial provision made by a husband to his wife when they are living apart. Alimony is now known as *maintenance or * financial provision. $^{23}$

وعرفها قاموس بلاك القانوني كالتالي:

Alimony. Comes from Latin "alimonia" meaning sustenance, and means, therefore, the sustenance or support of the wife by her divorced husband and stems from the common-law right of the wife to support • by her husband. ${ }^{24}$

و أخير انجد قاموس ميريام وبستر قد عرفها كما يلي:

Alimony: an allowance made to one spouse by the other for support pending or after legal separation or divorce. ${ }^{25}$

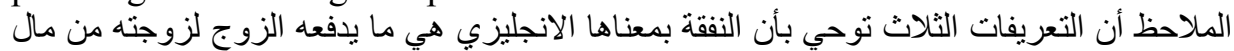

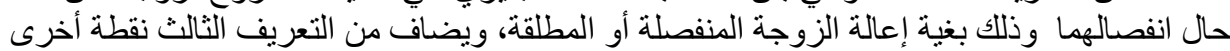

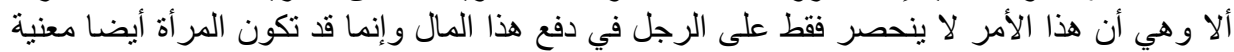

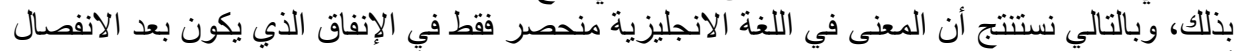

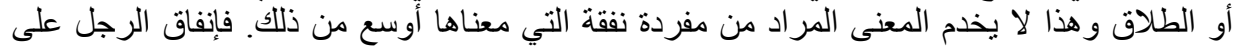

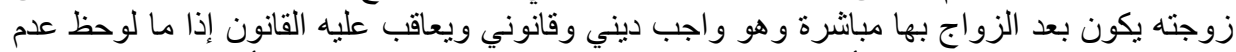

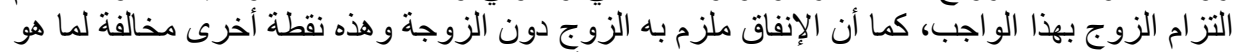

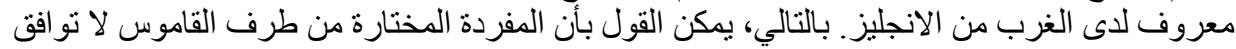

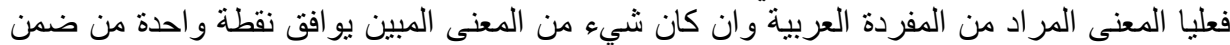

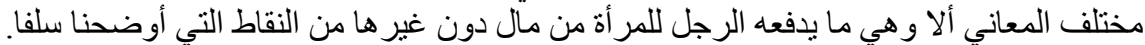
المفردة الثالثة:

الولي: والتي عرفها الثالة المعجم الوسيط على أنها كل من ولي أمر ا أو قام به، وفي السياقات التي نحن بصدد

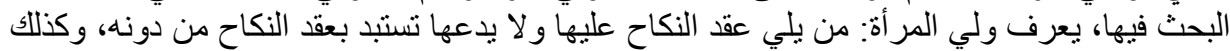

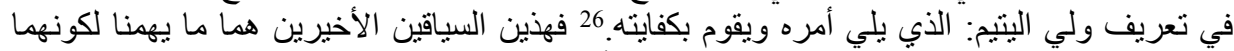

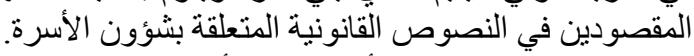

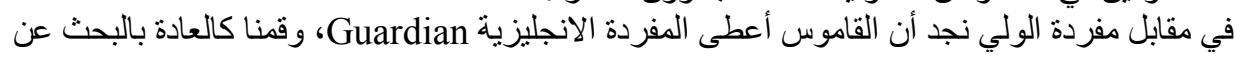

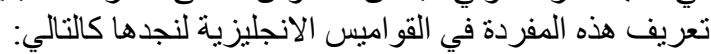
قاموس أوكسفورد القانوني: ت فئي

Guardian n. One who is formally appointed to look after a child's interests when the parents of the child do not have *parental responsibility for him or have died. Appointment can be made either by the courts during *family proceedings, if it is considered necessary for the child's welfare, or privately by any parent with parental responsibility. ${ }^{27}$

قاموس بلاك القانوني:

Guardian. A guardian is a person lawfully invested with the power, and charged with the duty, of taking care of the person and managing the property and rights of another person, who, for some peculiarity of status, or defect of 
age, understanding, or self-control, is considered incapable of administering his own affairs. ${ }^{28}$

Guardian: one who has or is entitled or legally appointed to the care and management of the person or property of another. ${ }^{29}$

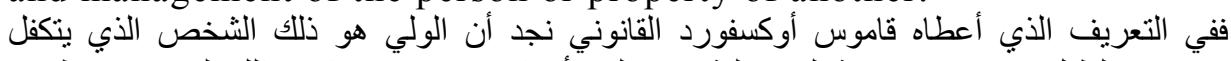

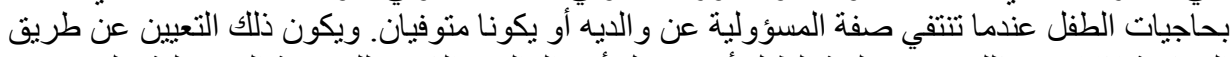

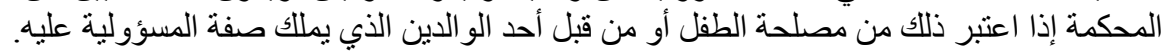

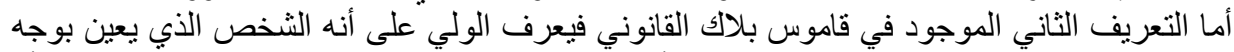

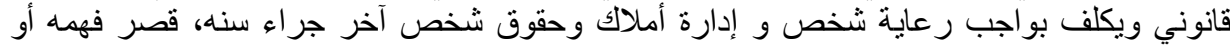
التحكم في قو اه العقلية.

أما بالنسبة إلى قاموس ميريام وبستر فقد عرف الولي على أنه ذلك الثخص المعين بصفة قانونية لرعاية و إدارة شؤون شخص إلى أو ملكية الغير.

إذن، نجد أن التعريف الأول يختلف عن التعريفين التاليين من حيث صفة الثنة الثخص المتكفل به، ألا و هو

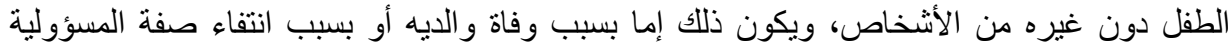

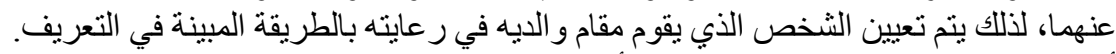

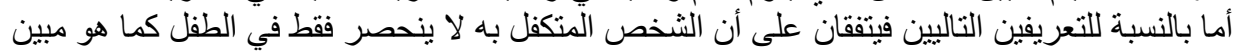

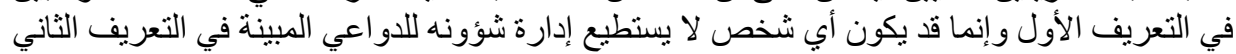

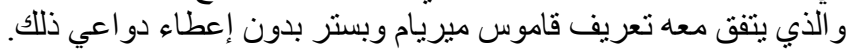

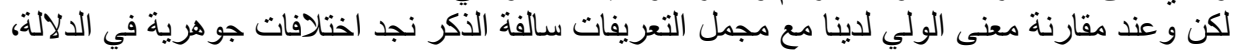

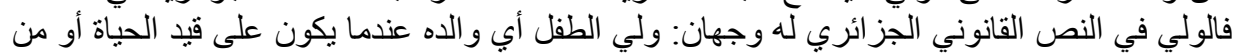

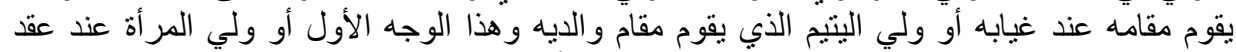

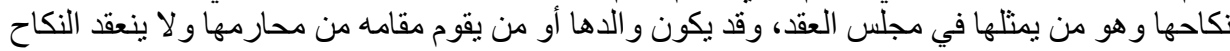
إلا بوجوده، و هذا هو الوجه الثاني.

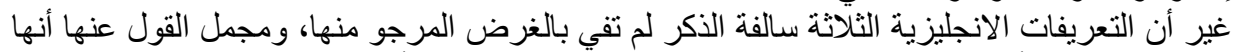

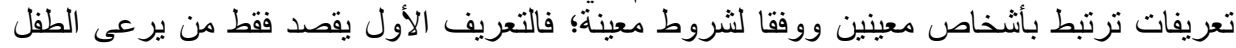

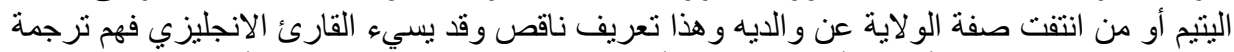

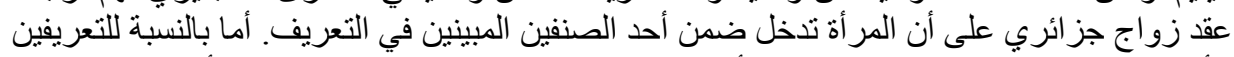

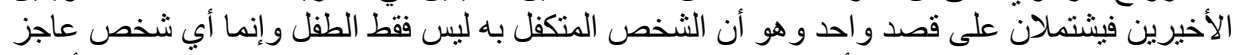

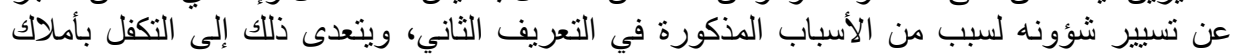

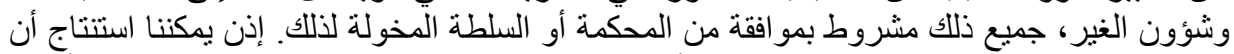
المفردة الانجليزية المختارة لا تثمل جميع الأوجه الدالية التي تعكسها مفردة الولي كما سبق وأشرنا

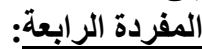

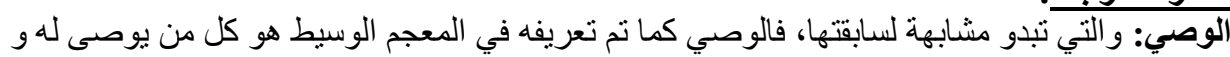

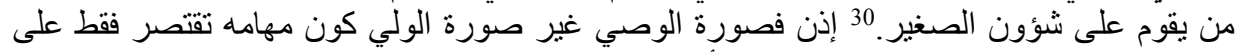

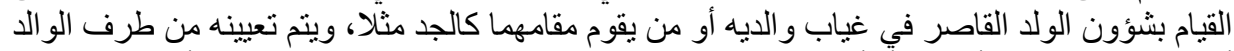

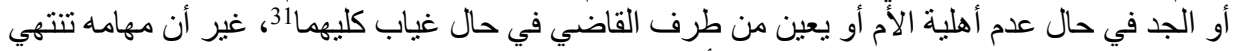

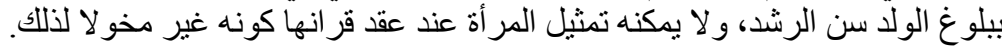

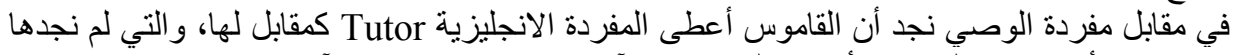
في قاموس أوكسفورد القانوني، أما في القاموسين الآنرين الآخرين وجدنا تعريفها كالآتي:

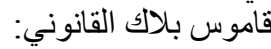


Tutor: In the civil law. This term corresponds nearly to "guardian," (i. e., a person appointed to have the care of the person of a minor and the administration of his estate,) except that the guardian of a minor who has passed a certain age is called "curator," and has powers and duties differing somewhat from those of a tutor. ${ }^{32}$

Tutor: in the civil law of Louisiana: a guardian of a minor or

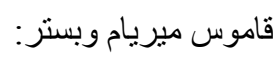
sometimes of a person with mental retardation. ${ }^{33}$

الملاحظ أن هناك تطابق في المفاهيم بين التعريف العربي و التعريفين الانجليزيين لمفردة الوصي، حيث

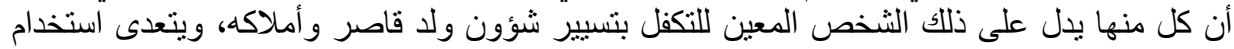

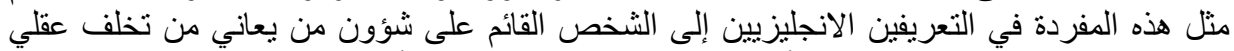

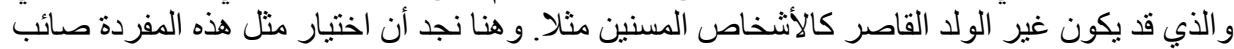

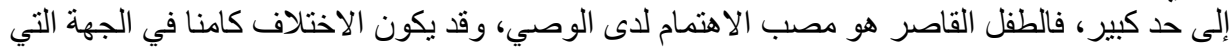
تعين الوصي للقيام بهذه المهام كما أسلفنا ذكره بالنسبة لكيفية تعيينه في قانون الأنية الأسرة الجزائري.

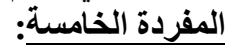
الإقوق: والتي نجدها في المعجم الوسيط كما يلي: عق أباه عقا وعقو قاو ومعقة: استخف به و عصاه وترك

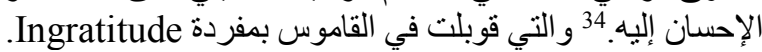

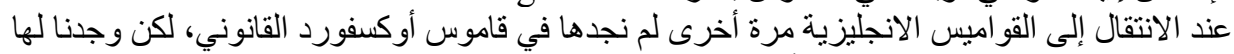
تعريفين في القاموسين الآخرين كما باتني:

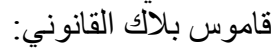

Ingratitude. In Roman law, ingratitude was accounted a sufficient cause for revoking a gift or recalling the liberty of a freedman. Such is also the law of France, with respect to the first case. But the English law has left the matter entirely to the moral sense. ${ }^{35}$

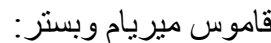

Ingratitude: forgetfulness of or lack of appreciation for kindness or especially a gift received. ${ }^{36}$

عندما نقوم بتحليل التعريف الأول من قاموس بلاك القانوني نجد أنه لم يقم بتعريف المفردة و إنما قام

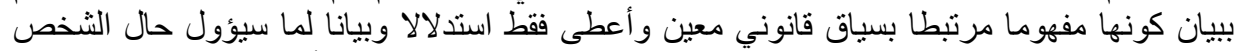

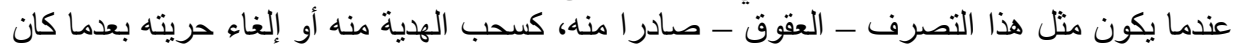

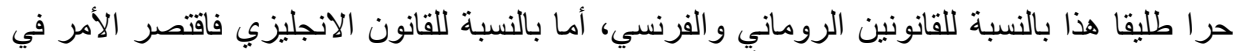

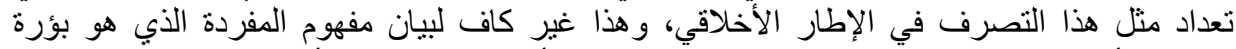

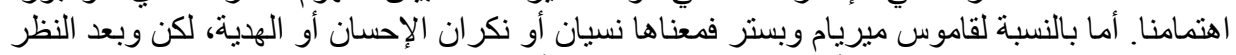

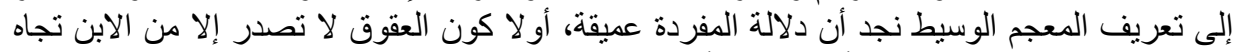

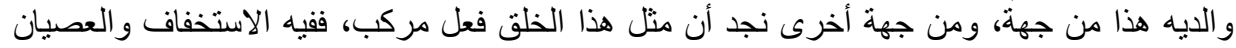

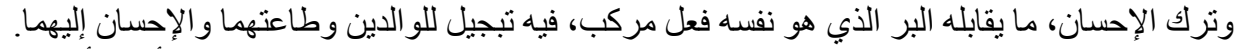

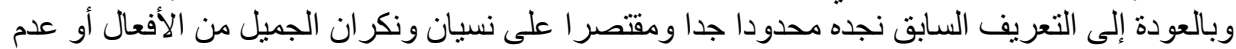

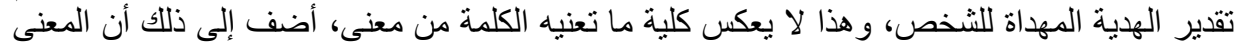

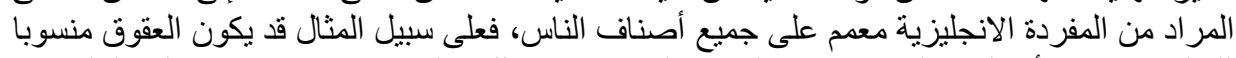

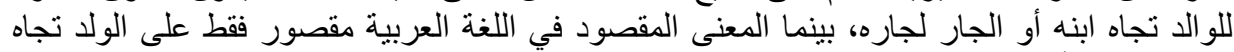
و الديه وبين الأمرين تباين و اختلاف كبيرين. 
عبارة ولد الفراشة: والتي لهام ارتباط وثثيق بالنسب والعلاقات الأسرية، حيث لم نجد تعريفا لجميع

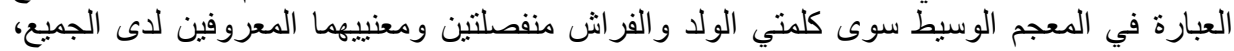

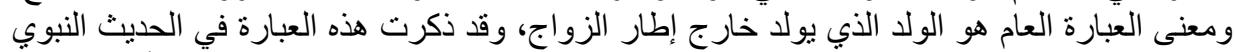

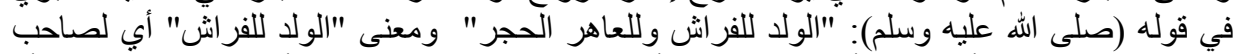

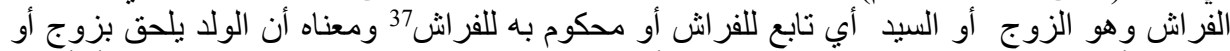

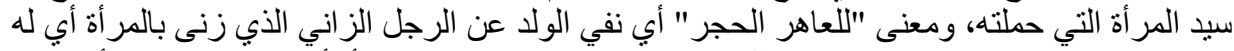

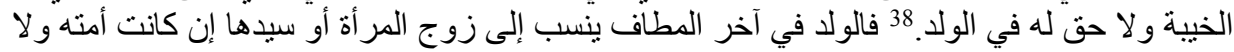

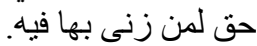

قوبلت هذه العبارة في القاموس بعبارة مثلها لكن باللغة اللاتينية مع ترجمة باللغة الانجليزية هكذا: Pater is est quem nuptiae demonstrant

The father is he whom the marriage points out بعد تصفحنا لقاموس أوكسفورد القانوني لم نجد لهذه العبارة وجود البتة، كذللك الأمر بالنسبة لقاموس

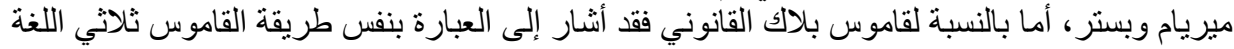
مع إضافة ترجمة باللغة الانجليزية كالتالي:

Pater is est quem nuptle remonstrant. The father is he whom the marriage points out. ${ }^{39}$

عند بحثنا عن استعمال هذه العبارة اللاتينية وجدنا أن أغلب الدول الغربية تعمل بها في قو انينها المتعلقة

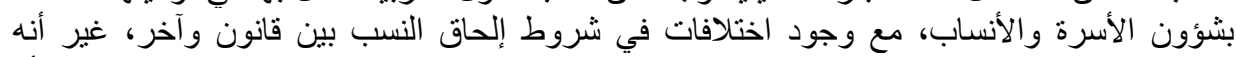

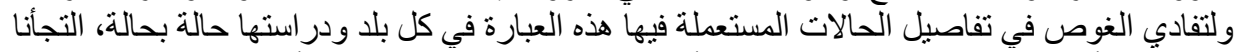

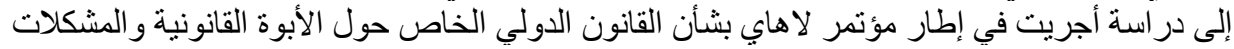

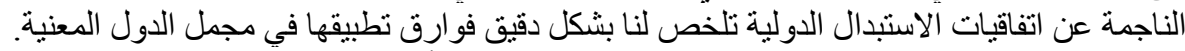

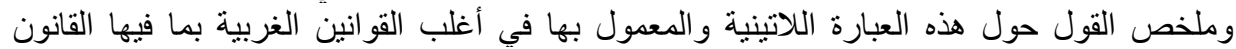

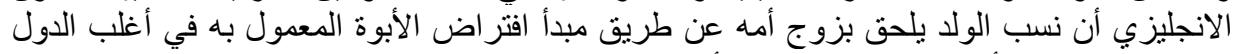

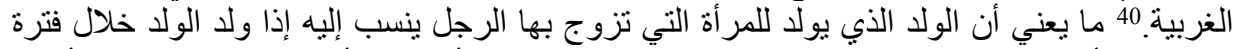

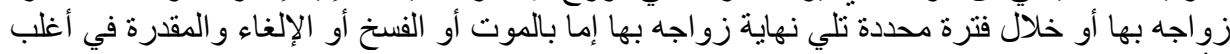

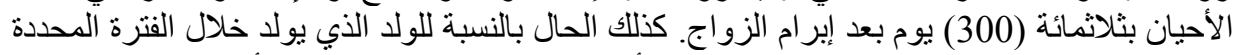

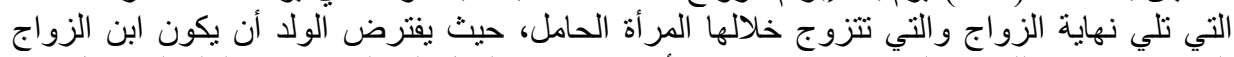

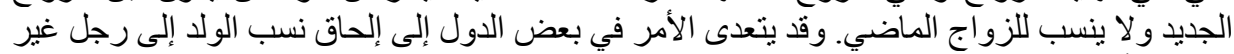

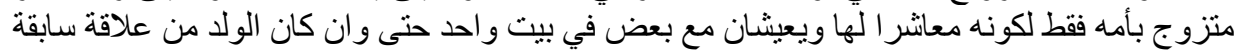

ما يعني في الحالتين الأوليين أن الولد قد يكون الابن الثرعي لمن نسب له أو قد لا يكون من صلبه البتة،

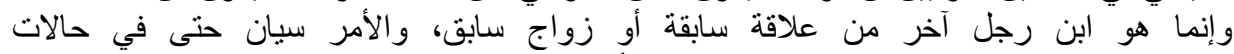

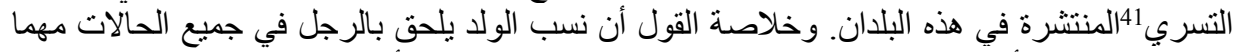

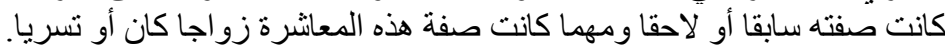

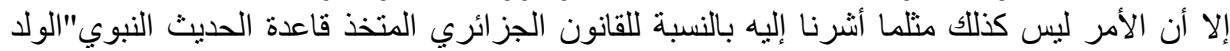

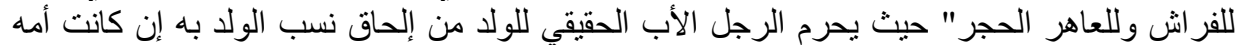

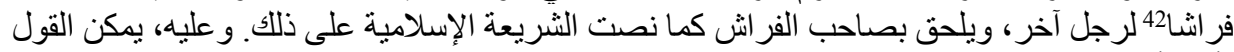

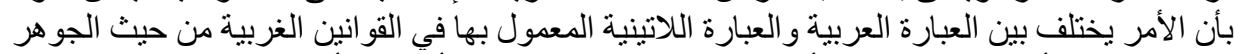

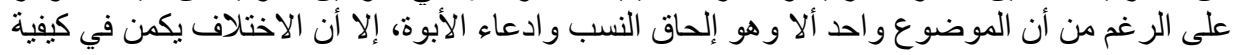


إلحاق النسب وصفة العلاقة التي في خضمها يتم إلحاق نسب الولد، و هنا بطرح مرة أخرى السؤال حول صحة اختيار مثل هذه المقابلات للمفردات ذات الدئل الدالة الثقافية العميقة.

المفردة السادسة:

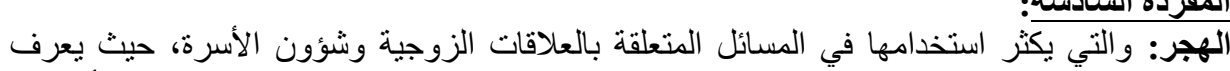

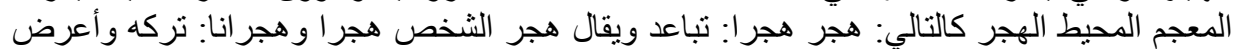
عنه ويقال: هجر زوجته: العتزل عنها ولم بطلقها. 43 تمت مقابلة هذه المفردة في القاموس بالعبارة العبارة

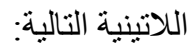

Divorce a mensa et thoro

$$
\text { ونجد قاموس أوكسفورد القانوني قد عرفها بـ : }
$$

A mensa et thoro [Latin] From board and bed. A decree of divorce a mensa et thoro was the forerunner of the modern judicial separation order. ${ }^{44}$ و الذي أحالنا إلى البحث عن المصطلح المعاصر المسمى "أمر الفصل القضائي" في جهة أخرى من

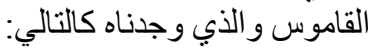

Judicial separation order An order by the courts that a husband and wife do not have to cohabit. The order does not terminate the marriage but it does free the parties of marital obligations. Judicial (or legal) separation is appropriate when there are religious objections to divorce or when the parties have not finally decided upon divorce. The grounds for separation are the same as those for *divorce. The courts have the same powers in relation to financial orders and children as they do when granting a divorce..$^{45}$

و عند تصفحنا لقاموس بلاك القانوني وجدنا:

A MENSA ET THORO. Lat. From table and bed, but more commonly translated, from bed and board. A kind of divorce, which is rather a separation of the parties by law, than a dissolution of the marriage. 27 C.J.S., Divorce, $\S$ $160 .{ }^{46}$

Divorce a mensa et thoro. A divorce from table and bed, or from bed and board. A partial or qualified divorce, by which the parties are separated and forbidden to live or cohabit together, without affecting the marriage itself. ${ }^{47}$

$$
\text { كما نجد قاموس ميريام وبستر قد عرف المصطلح كما يلي: }
$$

Divorce a mensa et thoro : A separation governed by a court order : LEGAL SEPARATION. ${ }^{48}$

ينتين من خلال ما وضعه كل من القو اميس الثثلاثة من نعريفات أن هذا المصطلح يعكس إجراءا قانونيا

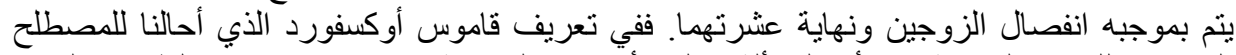

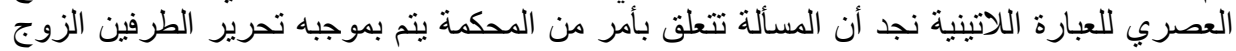

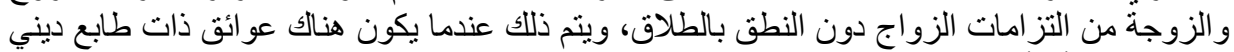

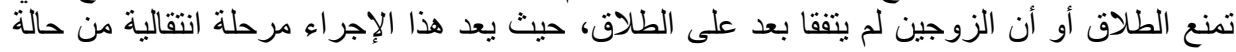

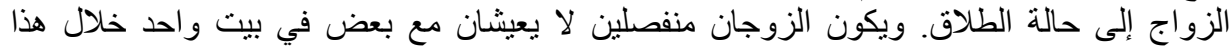

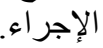

من جهة أخرى نجد أن قاموس بلاك القانوني قد نعته بالطلاق الذي يتم من خلاله الفصال الزبال الزوجين

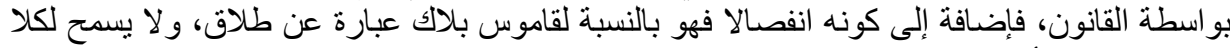

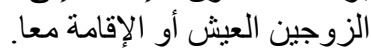




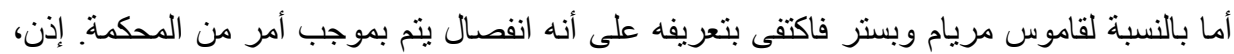

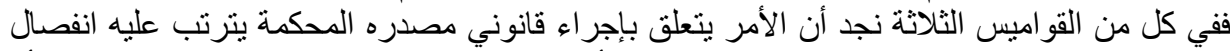

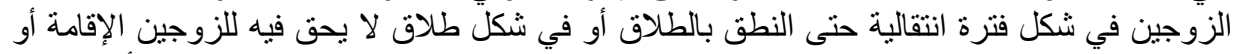

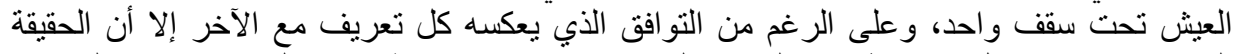

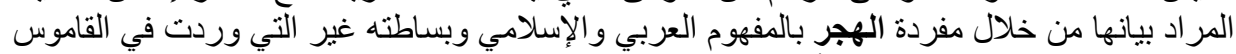

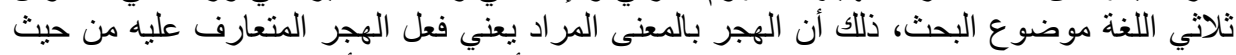

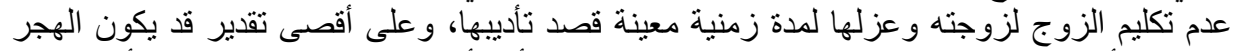

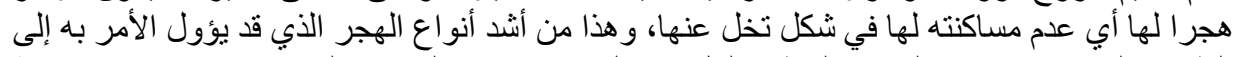

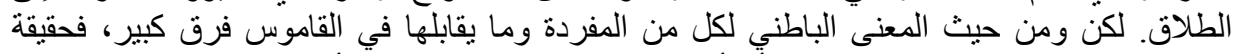

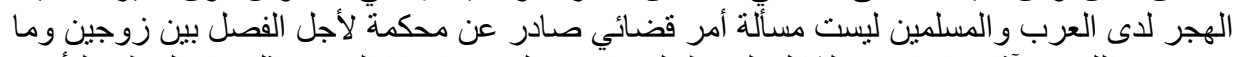

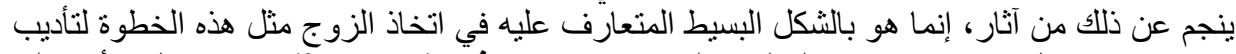

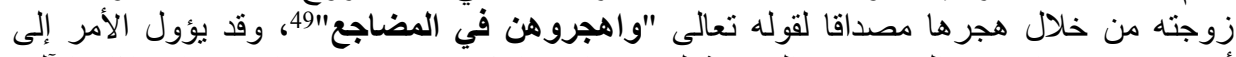

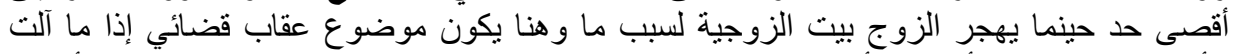

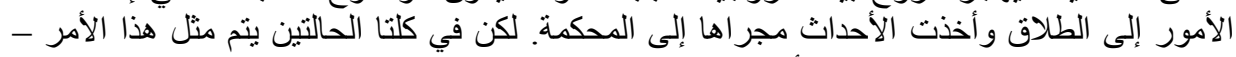

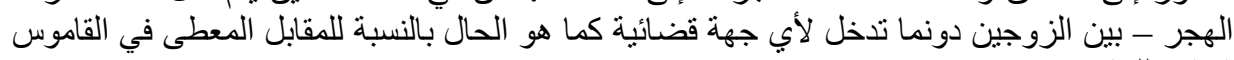
ثلاثي اللغة.

في ضوء ما توصلنا إليه من خلال دراستتا لكل مفردة من المفردات المختارة يمكن القول أن المقابل الدابل

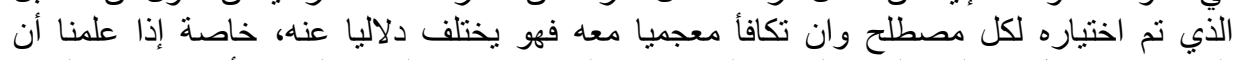

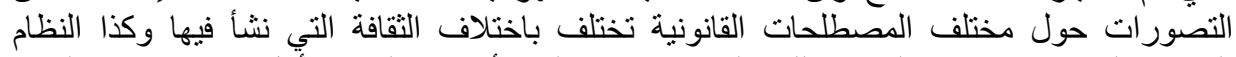

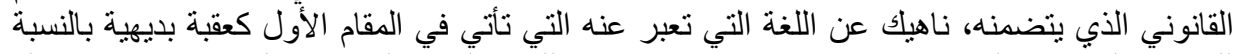

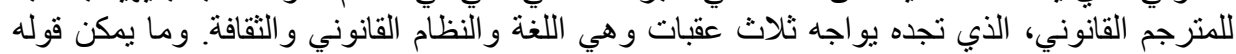

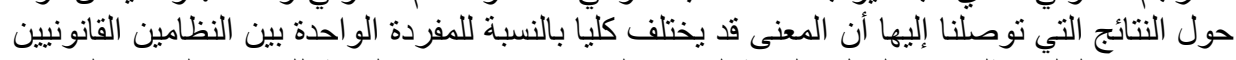

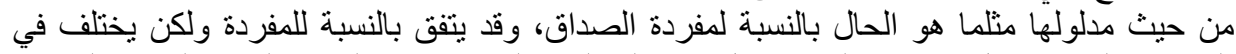

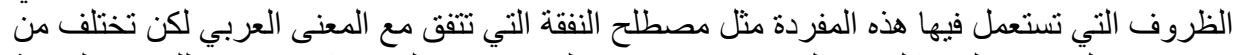

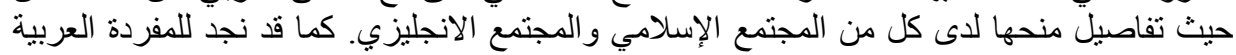

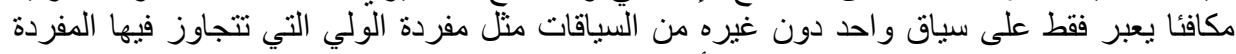

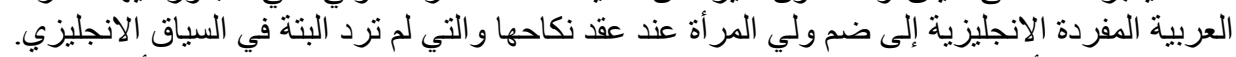

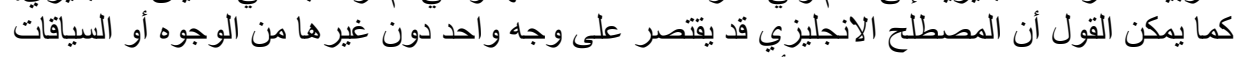

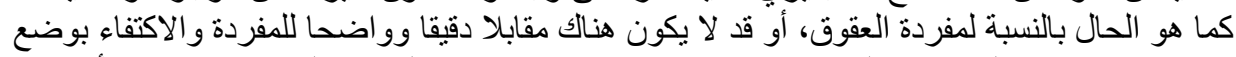

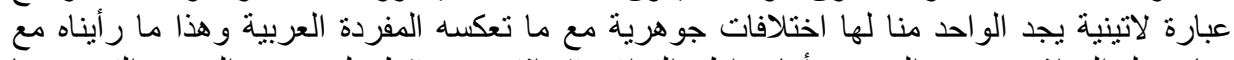

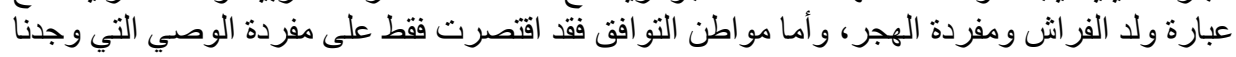
فيها تو افقا وتكافئا مع المفردة الانجليزية التي تقابلها.

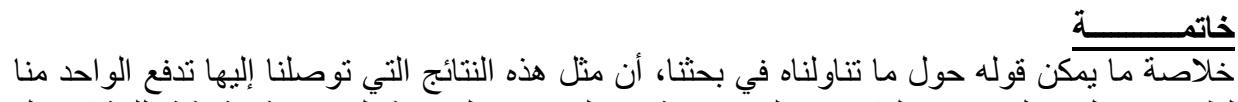

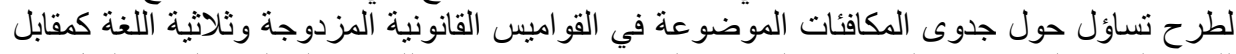

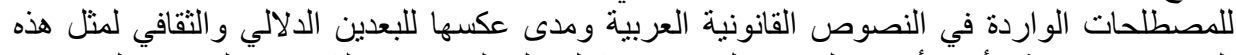

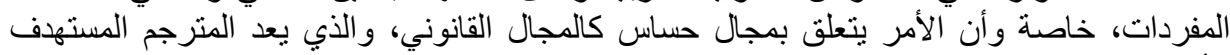

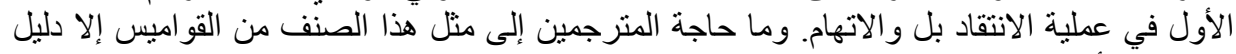

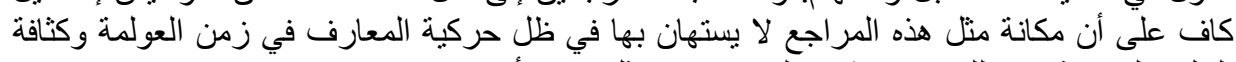

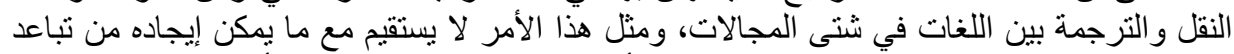
بين المصطلح وما يقابله من مصطلح في اللغة الأخرى، خاصة عندما ينعلق الأمر بمصطلحات ذاتئ ذات 


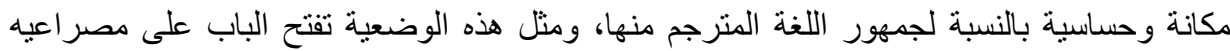

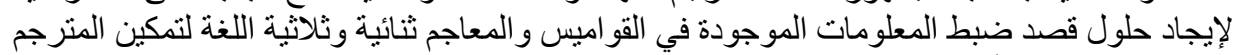
من آدائه عمله على أتم وجها فلبه

1- Nida, E., (1977), “Translating Means Communicating": A Sociolinguistic Theory of Translation, Georgetown University Press.

2- Guidère, Mathieu (coord.) (2009), «Traduction et communication orientée », Recherche - Université (de Genève), Paris, éditions Le Manuscrit, collection Parallèles. p. 18

3- Awaiss, Henri, Abou Fadel Saad, Gina, (2008), « Quand la parole de Dieu passe par la plume du traducteur ». Atelier de la Traduction. Numéro 9. p. 46 4- Mounin, Georges, (1963), «Problèmes théoriques de la traduction », Collection Tel ( ${ }^{\circ}$ 5), Gallimard, p. 196.

5- Berman, A.,(1984), « L'Epreuve de l'étranger ». Culture et traduction dans l'Allemagne romantique, Paris, Gallimard, p. 287.

6- Lederer, Mariane apud Teodora Cristea (1998), « Stratégies de la traduction », Ed. Fundaţiei România de Mâine, Bucureşti, p. 179.

7- En Français : Localisation

8- Sprung, R. C. (2000): "Introduction”, dans R. C. Sprung (dir.), Translating into Success : Cutting-Edge Strategies for Going Multilingual in a Global Age, Amsterdam/Philadelphia, John Benjamins, p.9.

9- Mi-Yeon Jeon et Brisset Annie (2006), «La notion de culture dans les manuels de traduction: domaines allemand, anglais, coréen et français " Meta : journal des traducteurs / Meta: Translators' Journal, vol. 51, n 2, p.391

10- Meschonnic, Henri (1999) : «Poétique du traduire », Paris, Verdier. p17.

11- Chosification " ومعناها التحول إلى المادية البحتة (200)

12- Guidère, Mathieu (coord.) (2010) : «Traduction et médiation

humanitaire », Recherche - Université (de Genève), Paris, éditions Le

Manuscrit, collection Parallèles. p. 207

13- Bassnett, Susan et Lefevere, André, (1998), « Constructing Cultures.

Essays on Literary Translation”, Clevedon etc., Multilingual Matters, , p.138.

14- Gémar, J-C,(1995). Traduire ou l'art d'interpréter, Langues, Droit et Société : éléments de jurilinguistique; Tome2, Presses de l'université du Québec, Canada. p.155

15-Gémar,JC, in Pelage, Jacques, La traduction du discours juridiques

Problématique et Méthodes, Edité par

l'auteur, Paris, 2007, p.21.

16- Cité par Depré Oseki. Inès, (2001). Questions de traductologie, Paris, Université de Provence, p.3 
17- Version électronique des rapports nationaux présentés au XVIIIe Congrès international de droit comparé sur le thème «La culture juridique et l'acculturation du droit», préparée par la Revue Juridique de l'Isaidat pour la Società Italiana di Ricerca nel Diritto Comparato (SIRD).p.1. Lien de l'article : isaidat.di.unito.it/index.php/isaidat/article/view/56/66

18- Newmark, P.,( 1988) “A Textbook of Translation”, London, Prentice Hall. 19- المعجم الوسيط، مجمع اللغة العربية بالقاهرة، الطبعة الرابعة (2004)، مكتبة الثروق الدولية،

20- Black's Law Dictionary, Henry Campbell Black, M. A. ST. Paul, Minn. West publishing co.1968. P.581

21- Merriam Webster Online dictionary 22- المعجم الوسيط، مجمع اللغة العربية بالقاهرة، الطبعة الرابعة (2004)، مكتبة الثروق الدولية، ص

23- Oxford dictionary of law, oxford university press, $5^{\text {th }}$ edition, 2003, P.23

24- Black's Law Dictionary, Henry Campbell Black, M. A. ST. Paul, Minn.

West publishing co.1968. P.97

25- Merriam Webster Online dictionary

26- المعجم الوسيط، مجمع اللغة العربية بالقاهرة، الطبعة الرابعة (2004)، مكتبة الثروق الدولية، ص

27- Oxford dictionary of law, oxford university press, $5^{\text {th }}$ edition, 2003, P.224

28- Black's Law Dictionary, Henry Campbell Black, M. A. ST. Paul, Minn.

West publishing co.1968. P.834

29- Merriam Webster Online dictionary

$$
\text { 31-30 المعجم الوسيط، مجمع اللغة العربية بالقاهرة، الطبعة الرابعة (2004)، مكتبة الثروق الدولية، }
$$

32- Black's Law Dictionary, Henry Campbell Black, M. A. ST. Paul, Minn.

West publishing co.1968. P.1687

33- Merriam Webster Online dictionary

34- المعجم الوسيط، مجمع اللغة العربية بالقاهرة، الطبعة الرابعة (2004)، مكتبة الثروق الدولية، ص -

35- Black's Law Dictionary, Henry Campbell Black, M. A. ST. Paul, Minn.

West publishing co.1968. P.92

36- Merriam Webster Online dictionary

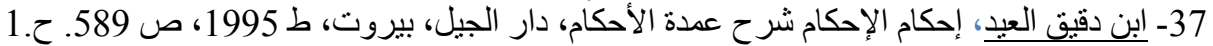

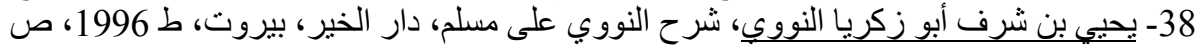

39- Black's Law Dictionary, Henry Campbell Black, M. A. ST. Paul, Minn. West publishing co.1968. P.1282 
40- Hague conference on private international law "A study of legal parentage and the issues arising from international surrogacy arrangements", March 2014. The Hague - The Netherlands. PP. 8-9

41- Concubinage

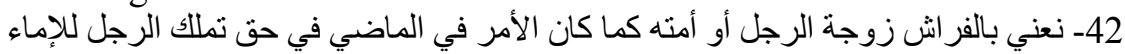

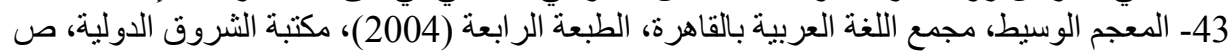

44- Oxford dictionary of law, oxford university press, $5^{\text {th }}$ edition, 2003. P. 25

45- Ibid. P. 272

46- Black's Law Dictionary, Henry Campbell Black, M. A. ST. Paul, Minn.

West publishing co.1968. P.06

47- Ibid. P.566

48- Merriam Webster Online dictionary

49- سورة النساء، الآية 34 